\title{
Facial palsy in children: long-term outcome assessed face-to-face and follow-up revealing high recurrence rate
}

\author{
Mervi Kanerva $^{1}$ (D) Hanna Liikanen ${ }^{2} \cdot$ Anne Pitkäranta $^{1}$
}

Received: 26 September 2020 / Accepted: 5 November 2020 / Published online: 15 December 2020

(c) The Author(s) 2020

\begin{abstract}
Purpose To evaluate the long-term (minimum of 2 years from the palsy onset) outcome of pediatric facial palsy by patient questionnaire and face-to-face assessment by the Sunnybrook facial grading system, House-Brackmann grading system, and Facial Nerve Grading System 2.0. To compare the outcome results of self-assessment with the face-to-face assessment. To assess the applicability of the grading scales. To assess the palsy recurrence rate (minimum of a 10-year follow-up). Methods 46 consecutive pediatric facial palsy patients: 38 (83\%) answered the questionnaire and $25(54 \%)$ attended a followup visit. Chart review of 43 (93\%) after a minimum of 10 years for the facial palsy recurrence rate assessment.

Results Of the 25 patients assessed face-to-face, $68 \%$ had totally recovered but $35 \%$ of them additionally stated subjective sequelae in a self-assessment questionnaire. Good recovery was experienced by $80 \%$ of the patients. In a 10 -year follow-up, $14 \%$ had experienced palsy recurrence, only one with a known cause. Sunnybrook was easy and logical to use, whereas House-Brackmann and the Facial Nerve Grading System 2.0 were incoherent.

Conclusions Facial palsy in children does not heal as well as traditionally claimed if meticulously assessed face-to-face. Patients widely suffer from subjective sequelae affecting their quality of life. Palsy recurrence was high, much higher than previously reported even considering the whole lifetime. Of these three grading systems, Sunnybrook was the most applicable.
\end{abstract}

Keywords Facial paralysis · Sunnybrook $\cdot$ House-Brackmann · Facial Nerve Grading System 2.0 $\cdot$ Synkinesis $\cdot$ Child

\section{Introduction}

If peripheral facial palsy (FP) does not recover fully, cosmetic drawback for the patient is obvious, but the effect on vision, eating, drinking, psychological issues, self-esteem, and quality of life are easily overlooked, although well established [1]. This applies also to situations where voluntary muscle function has recovered quite well but the patient is nonetheless affected by sequelae [2, 3]. Synkineses (voluntary movements accompanied by involuntary movements, e.g., eye closure with mouth movements), contractures, and hemifacial spasms all are post-palsy sequelae.

Mervi Kanerva

mervi.kanerva@gmail.com

1 Department of Otorhinolaryngology-Head and Neck Surgery, Helsinki University Hospital and University of Helsinki, Helsinki, Finland

2 Department of Orthopedics and Traumatology, Helsinki University Hospital and University of Helsinki, Helsinki, Finland
It has been a common claim that children recover well from FP. This claim has been based on retrospective studies mostly with short follow-up periods [4-11]. Prospective studies on solely pediatric FP patients are sparse.

A reliable grading method is required to be able to assess and communicate FP outcome, and this is currently lacking. Objective methods are being developed but are not yet in wider clinical use. The most used subjective method is the House-Brackmann grading system (HB) (Table 1) [12], although its suitability for present-day demands has been questioned [13-15]. A revised version, the Facial Nerve Grading System 2.0 (FNGS) (Table 2) [16] was developed but has not gained popularity. On the other hand, the use of the Sunnybrook facial grading system (SB) (Table 3) [17, $18]$ is growing among investigators [14, 19].

The aim of this study was to assess the long-term (minimum of 2 years) outcome of pediatric FP using a patient/ caregiver self-assessment FP outcome questionnaire and by face-to-face grading using HB, FNGS, and SB concomitantly. The second aim was to compare the applicability of the grading scales. Third, we wanted to know whether patient 
Table 1 House-Brackmann grading system [12]

\begin{tabular}{|c|c|c|}
\hline Grade & Description & Characteristics \\
\hline I & Normal & Normal facial function in all areas \\
\hline II & Mild dysfunction & $\begin{array}{l}\text { Gross: Slight weakness noticeable on close inspection; may have very slight synkinesis } \\
\text { At rest: Normal symmetry and tone } \\
\text { Motion: Forehead: moderate to good function } \\
\text { Eye: complete closure with minimal effort } \\
\text { Mouth: slight asymmetry }\end{array}$ \\
\hline III & Moderate dysfunction & $\begin{array}{l}\text { Gross: Obvious but not disfiguring difference between two sides; noticeable but not } \\
\text { severe synkinesis, contracture, and/or hemifacial spasm } \\
\text { At rest: Normal symmetry and tone } \\
\text { Motion: Forehead: slight to moderate movement } \\
\text { Eye: complete closure with effort } \\
\text { Mouth: slightly weak with maximum effort }\end{array}$ \\
\hline IV & Moderately severe dysfunction & $\begin{array}{l}\text { Gross: Obvious weakness and/or disfiguring asymmetry } \\
\text { At rest: Normal symmetry and tone } \\
\text { Motion: Forehead: none } \\
\text { Eye: incomplete closure } \\
\text { Mouth: asymmetric with maximum effort }\end{array}$ \\
\hline V & Severe dysfunction & $\begin{array}{l}\text { Gross: Only barely perceptible motion } \\
\text { At rest: Asymmetry } \\
\text { Motion: Forehead: none } \\
\text { Eye: incomplete closure } \\
\text { Mouth: slight movement }\end{array}$ \\
\hline VI & Total paralysis & No movement \\
\hline
\end{tabular}

Table 2 Facial Nerve Grading System 2.0 [16]

\begin{tabular}{|c|c|c|c|c|c|}
\hline \multicolumn{6}{|c|}{ Region } \\
\hline Score & Brow & \multicolumn{2}{|l|}{ Eye } & Nasolabial fold & Oral \\
\hline 1 & Normal & \multicolumn{2}{|l|}{ Normal } & Normal & Normal \\
\hline 2 & $\begin{array}{l}\text { Slight weakness } \\
>75 \% \text { of normal }\end{array}$ & \multicolumn{2}{|l|}{$\begin{array}{l}\text { Slight weakness } \\
>75 \% \text { of normal } \\
\text { Complete closure with mild effort }\end{array}$} & $\begin{array}{l}\text { Slight weakness } \\
>75 \% \text { of normal }\end{array}$ & $\begin{array}{l}\text { Slight weakness } \\
>75 \% \text { of normal }\end{array}$ \\
\hline 3 & $\begin{array}{l}\text { Obvious weakness } \\
>50 \% \text { of normal } \\
\text { Resting symmetry }\end{array}$ & \multicolumn{2}{|l|}{$\begin{array}{l}\text { Obvious weakness } \\
>50 \% \text { of normal } \\
\text { Complete closure with maximal effort }\end{array}$} & $\begin{array}{l}\text { Obvious weakness } \\
>50 \% \text { of normal } \\
\text { Resting symmetry }\end{array}$ & $\begin{array}{l}\text { Obvious weakness } \\
>50 \% \text { of normal } \\
\text { Resting symmetry }\end{array}$ \\
\hline 4 & $\begin{array}{l}\text { Asymmetry at rest } \\
<50 \% \text { of normal }\end{array}$ & \multicolumn{2}{|l|}{$\begin{array}{l}\text { Asymmetry at rest } \\
<50 \% \text { of normal } \\
\text { Cannot close completely }\end{array}$} & $\begin{array}{l}\text { Asymmetry at rest } \\
<50 \% \text { of normal }\end{array}$ & $\begin{array}{l}\text { Asymmetry at rest } \\
<50 \% \text { of normal }\end{array}$ \\
\hline 5 & Trace movement & \multicolumn{2}{|l|}{ Trace movement } & Trace movement & Trace movement \\
\hline 6 & No movement & \multicolumn{2}{|l|}{ No movement } & No movement & No movement \\
\hline \multicolumn{6}{|c|}{ Secondary movement (global assessment) } \\
\hline \multicolumn{3}{|l|}{ Score } & \multicolumn{3}{|c|}{ Degree of movement } \\
\hline \multicolumn{3}{|l|}{0} & \multicolumn{3}{|l|}{ None } \\
\hline \multicolumn{3}{|l|}{1} & \multicolumn{3}{|c|}{ Slight synkinesis; minimal contracture } \\
\hline \multicolumn{3}{|l|}{2} & \multicolumn{3}{|c|}{ Obvious synkinesis; mild to moderate contracture } \\
\hline \multicolumn{3}{|l|}{3} & \multicolumn{3}{|c|}{ Disfiguring synkinesis; severe contracture } \\
\hline \multicolumn{6}{|c|}{ Reporting: sum scores for each region and secondary movement } \\
\hline \multicolumn{3}{|l|}{ Grade } & \multicolumn{3}{|l|}{ Total score } \\
\hline \multicolumn{3}{|l|}{ I } & \multicolumn{3}{|l|}{4} \\
\hline \multicolumn{3}{|l|}{ II } & \multicolumn{3}{|l|}{$5-9$} \\
\hline \multicolumn{3}{|l|}{ III } & \multicolumn{3}{|l|}{$10-14$} \\
\hline \multicolumn{3}{|l|}{ IV } & \multicolumn{3}{|l|}{ 15-19 } \\
\hline \multicolumn{3}{|l|}{ V } & \multicolumn{3}{|l|}{$20-23$} \\
\hline \multicolumn{3}{|l|}{ VI } & \multicolumn{3}{|l|}{24} \\
\hline
\end{tabular}




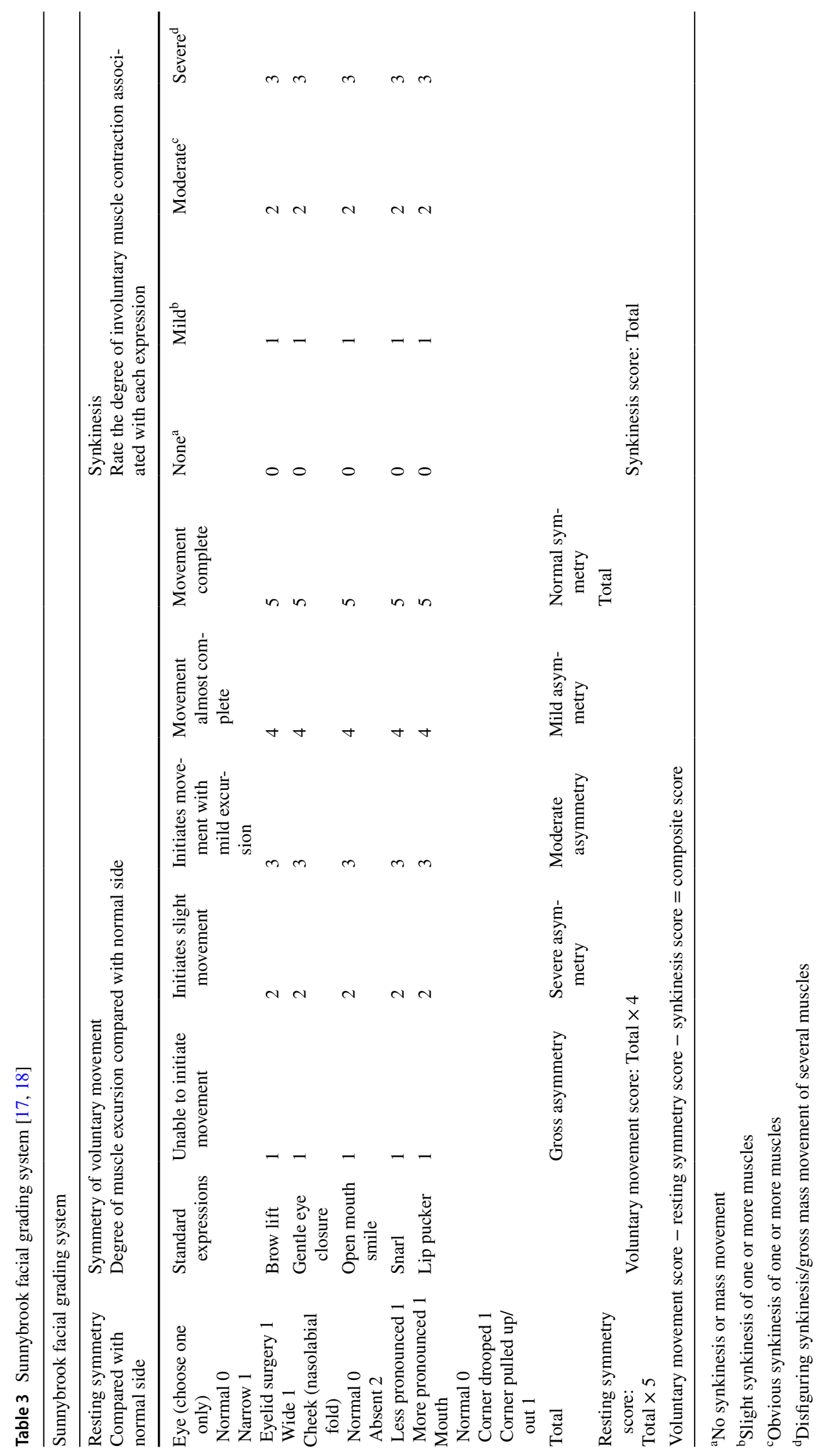


Table 4 Synkinesis Assessment Questionnaire [21]

Please answer the following questions regarding facial function, on a scale from 1 to 5 , according to the following scale:

$1=$ seldom or not at all

2 = occasionally, or very mildly

$3=$ sometimes, or mildly

$4=$ most of the time, or moderately

$5=$ all the time, or severely

A. When I smile, my eye closes

B. When I speak, my eye closes

C. When I whistle or pucker my lips, my eye closes

D. When I smile, my neck tightens

E. When I close my eyes, my face gets tight

F. When I close my eyes, the corner of my mouth moves

G. When I close my eyes, my neck tightens

H. When I eat, my eye waters

I. When I move my face, my chin develops a dimpled area

questionnaire self-assessed FP outcome results varied from gradings performed by the investigator. Fourth, after a minimum of 10 years from the FP onset, we assessed from the patient charts whether any new FP recurrences had occurred.

\section{Material and methods}

A prospective study of FP in children, with 46 children ( $\leq 16$ years), was conducted between May 2007 and August 2009 [20]. After a minimum of 2 years from the palsy onset, the study patients were requested to participate in a followup study. The recruitment letter contained an invitation to come for a one-time face-to-face FP grading session and a questionnaire for self/caregiver-assessment of the long-term FP outcome, recovery, and possible sequelae results; it also included the Synkinesis Assessment Questionnaire (SAQ) [21] (Tables 4, 5). Should the patients not wish to take part in the clinical examinations, they were able to take part in the study by returning the completed questionnaire.

In January 2020, after a minimum of 10 years from the palsy onset, the patient records for all the 46 patients taking part in the initial prospective study [20] were viewed to see whether any new palsy recurrences had appeared. If the patient did not take part in this current long-term outcome follow-up study, the outcome mentioned in the patient charts was recorded.

At the one-time visit, the corresponding author assessed the FP long-term outcome by the HB, FNGS, and SB grading methods.

For the prospective part (questionnaire and follow-up visit), the Helsinki University Hospital Ethics Committee approved the study, institutional research approval was granted, and all patients gave their written informed consent. For the retrospective chart study, the Department of Otorhinolaryngology-Head and Neck Surgery, Helsinki University Hospital, institutional research approval was requested and granted.

We used descriptive statistics to summarize the frequencies, proportions, means or medians, and ranges.

\section{Results}

\section{Patient characteristics}

Of the 46 patients, 38 (83\%) answered the questionnaire, and $25(54 \%)$ both answered the questionnaire and came to the follow-up visit.

Table 5 Study questionnaire (in addition to Synkinesis Assessment Questionnaire, see Table 4)

1. You had/your child had had facial palsy at least once at the time of our previous study. Have you/your child experienced facial palsy recurrence after that time? If so, when.

2. Are there any relatives who also have had facial palsy? If so, mark the kinship, no personal data of that person.

3. Do you/does your child have any of the following sequelae symptoms?
A. Post-palsy functional defects affecting speaking
B. Post-palsy functional defects affecting eating or drinking
C. Clicking or other sounds in the ear produced by mouth movements
D. Excessive tearing
E. Decreased tearing/dry eyes
F. Dry mouth
G. Facial area aches
H. Increased sensitivity to normal sounds
I. Something else, what? (Sequelae affecting outlooks, social situations, etc.)
4. Have you/your child fully recovered from facial palsy?
5. Do you/your child have any other diseases, if so, what?
6. Do you/your child use any regular medications, if so, what? 
Table 6 Synkinesis Assessment Questionnaire results from 37/38 patients (one unanswered)

\begin{tabular}{|c|c|c|c|c|c|}
\hline & $\begin{array}{l}\text { Severity } 1 \dagger \\
\text { Number of } \\
\text { patients }(\%)\end{array}$ & $\begin{array}{l}\text { Severity } 2 \dagger \\
\text { Number of } \\
\text { patients }(\%)\end{array}$ & $\begin{array}{l}\text { Severity } 3 \dagger \\
\text { Number of } \\
\text { patients }(\%)\end{array}$ & $\begin{array}{l}\text { Severity } 4 \dagger \\
\text { Number of } \\
\text { patients }(\%)\end{array}$ & $\begin{array}{l}\text { Severity } 5 \dagger \\
\text { Number } \\
\text { of patients } \\
\text { (\%) }\end{array}$ \\
\hline A. When I smile, my eye closes & $30(81)$ & 0 & $3(8)$ & $1(3)$ & $3(8)$ \\
\hline B. When I speak, my eye closes & $33(89)$ & 0 & $3(8)$ & 0 & $1(3)$ \\
\hline C. When I whistle or pucker my lips, my eye closes & $29(78)$ & $3(8)$ & $1(3)$ & $1(3)$ & $3(8)$ \\
\hline D. When I smile, my neck tightens & $33(89)$ & $3(8)$ & $1(3)$ & 0 & 0 \\
\hline E. When I close my eyes, my face gets tight & $33(89)$ & $2(5)$ & $1(3)$ & $1(3)$ & 0 \\
\hline F. When I close my eyes, the corner of my mouth moves & $33(89)$ & $1(3)$ & 0 & $1(3)$ & $2(5)$ \\
\hline G. When I close my eyes, my neck tightens & $37(100)$ & 0 & 0 & 0 & 0 \\
\hline H. When I eat, my eye waters & $36(97)$ & $1(3)$ & 0 & 0 & 0 \\
\hline I. When I move my face, my chin develops a dimpled area & $32(86)$ & $2(5)$ & 0 & $1(3)$ & $2(5)$ \\
\hline
\end{tabular}

${ }^{\dagger} 1=$ seldom or not at all; $2=$ occasionally, or very mildly; $3=$ sometimes, or mildly; $4=$ most of the time, or moderately; $5=$ all the time, or severely

At the time of FP onset, the median age of the 38 participants was 10.75 years (range $0.04-16.2$ years). Of them, $21(55 \%)$ were girls and $17(45 \%)$ were boys. FP was on the right side for $21(55 \%)$ cases, the left side for $15(39 \%)$, and was bilateral for $2(5 \%)$.

The median follow-up time since FP onset to the evaluation of FP outcome was 3.5 years (range 2.3-4.6 years).

At the time of the chart review for the FP recurrence evaluation, 10.3-12.6 years had passed from the FP onset.

\section{Facial palsy outcome}

\section{Questionnaire}

In the SAQ (Tables 6, 7), 14/37 (38\%) reported synkineses (1 child/caregiver had left the synkinesis part of the questionnaire blank). Other sequelae (Tables 5,7 ) were reported by 15/38 (39\%) patients as follows: $3 / 38(8 \%)$ sequelae affecting speaking, $3 / 38(8 \%)$ sequelae affecting eating or drinking, 4/38 (11\%) oro-aural synkinesis (mouth movements accompanied by clicking sounds in the ear), 4/38 (11\%) excessive tearing, 4/38 (11\%) dry eyes, $1 / 38$ (3\%) dry mouth, $1 / 38$ (3\%) facial ache, and 1/38 (3\%) hyperacusis (increased sensitivity to normal sounds). Additionally, 9/38 (24\%) had sequelae that hindered outlook or social situations.

\section{Face-to-face assessment}

Full recovery, subjective sequelae The FP outcome assessment was performed meticulously, also taking into account the slight synkineses or functional defects. Of the 25 patients assessed, 17 (68\%) were found by the assessor to be fully recovered (Table 7). Nonetheless, three of these patients/their caregivers had stated in the questionnaire that they did not feel fully recovered. They stated functional defects, synkineses in the SAQ (Tables 6, 7), and other sequelae (Table 7), although at the time of the assessment, these symptoms could not be detected by the assessor. An additional three patients found by the assessor to be fully recovered and who had also checked the full recovery box in their questionnaire, stated some synkineses in the SAQ (two patients, Tables 6,7 ) and other sequelae (all three patients, Table 7). Hence, out of those assessed by the investigator to be fully recovered, $5 / 17$ (29\%) reported synkineses in the SAQ and 6/17 (35\%) other additional sequelae in the selfassessment questionnaire.

Non-full recovery From the face-to-face assessment, 8/25 (32\%) of the patients had not fully recovered (Table 7): $7 / 25$ (28\%) had voluntary muscle function defects, 7/25 (28\%) had synkineses, and 5/25 (20\%) had asymmetry at rest. Three patients had an SB total score $\geq 90$; thus they were close to full recovery but not quite. Including them, 20/25 (80\%) patients had recovered very well, although not totally. The remaining 5/25 (20\%) patients had an SB total score $\leq 80$ (Table 7), here listed with the associative etiologic factor and the SB total score: neurofibromatosis, 37; varicella-zoster virus, 48; neuroborreliosis, 60; congenital, 64; and influenza A, 78.

Applicability of the grading scales It was impossible to place the FP outcome in only one HB grade for $4 / 8(50 \%)$ of the assessed patients who did not recover fully (Table 7). The voluntary movement outcome result was in disagreement with asymmetry at rest and/or synkinesis, and each finding would have placed the patient in a different HB grade. Accordingly, the use of FNGS could not be carried out without ignoring resting symmetry findings, which were in disagreement with the voluntary movement results in $2 / 8(25 \%)$ patients (Table 7). In other cases, FNGS and SB results were 


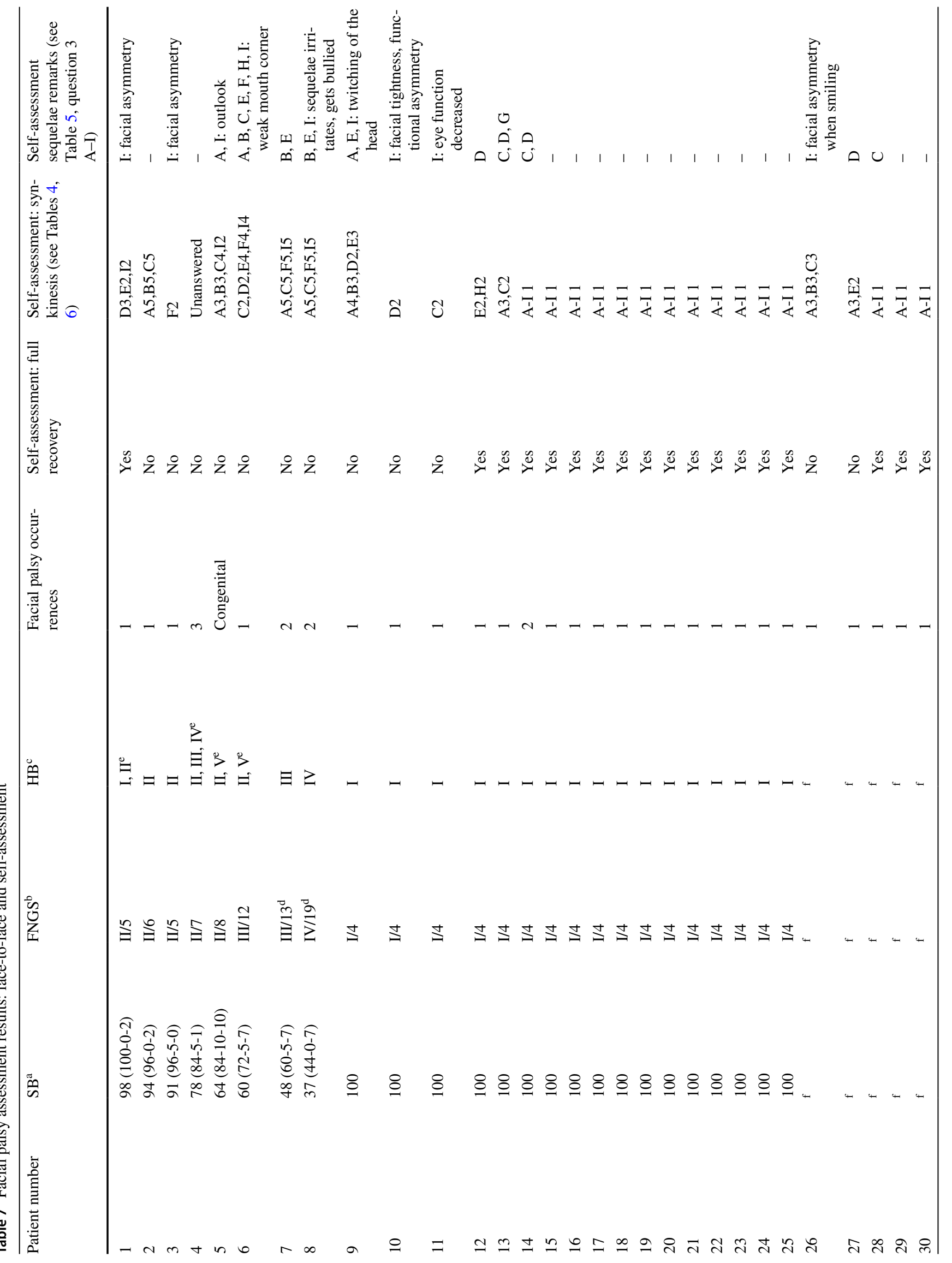




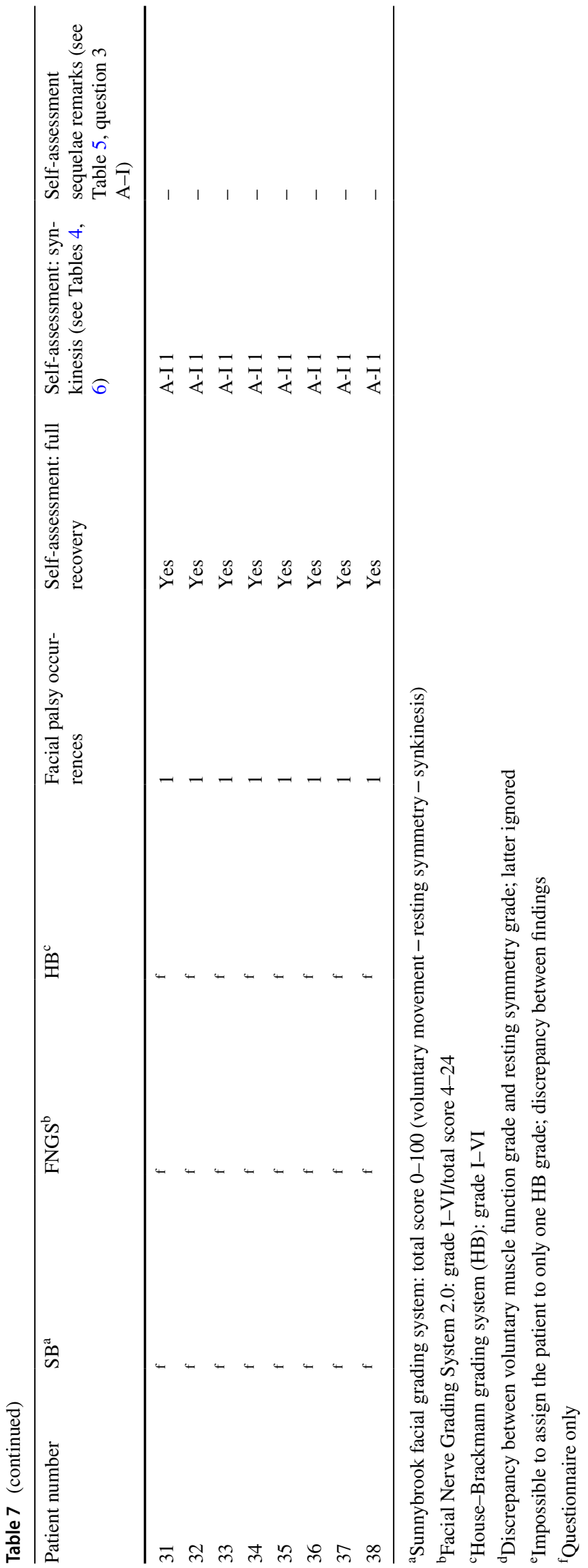

in concordance. FNGS proved to be better than HB, but SB was the most applicable of the three grading scales used.

Medications All patients with borreliosis received antibiotic treatment [20]. Four teenage patients with Bell's palsy received prednisolone; two of them recovered fully, two did not [20]. One patient with herpes association and total recovery received virus medication [20].

Age of patients: full recovery versus non-full recovery The median age (at the time of the FP onset) for the patients that had fully recovered according to the follow-up visit face-to-face assessment was 13.8 years (range 0.815.6 years) and for those non-fully recovered 6.9 years (range 0.04-15.1 years). Since the latter included one congenital FP, full recovery of that child was impossible: excluding her, the median age for those non-fully recovered was 7.5 years (range 1.5-15.1 years).

\section{Patient charts}

Of those 46 patients taking part in the initial etiology study [20], 8 did not take part in this follow-up study. From their patient charts it could be registered that five of them had fully recovered within a month and three had recovered to HB II, two within a month and one within 2 months from the FP onset (two of them were not scheduled any further follow-up visits and one was lost for follow-ups). We do know synkineses can develop in months to come even in patients whose voluntary muscle function has fully recovered [22]. Thus, we cannot definitely know whether even those five who rapidly fully recovered stayed fully recovered in the long run.

\section{Etiology and outcome}

From face-to-face assessments, we considered "fully recovered" those with an SB score of 100 and from the questionnaire-only patients those who had checked the box "fully recovered" (Table 7).

Neuroborreliosis was the main etiologic factor in 12/38 (32\%) of the patients studied. They all received antibiotic treatment [20]. Of them, six came to the face-toface assessment and 4/6 (67\%) were fully recovered. Six answered only the questionnaire and 5/6 (83\%) assessed themselves to be fully recovered. When face-to-face assessment and self-assessment results are combined, of the fully recovered patients $9 / 28(32 \%)$ were borreliosis patients and of the non-fully recovered patients $3 / 10$ $(30 \%)$. 
Association with varicella-zoster virus was present in $4 / 38(11 \%)$ of the cases [20]. Of them, $3 / 4(75 \%)$ recovered fully. Association with human herpesvirus-6 and herpes simplex virus-1 was in 4/38 (11\%) [20], of whom $3 / 4$ (75\%) recovered fully. Only one of them had received virus medication. Influenza A was detected at the same time as FP in $3 / 38(8 \%)$ of the patients [20] with $2 / 3(67 \%)$ recovering fully. The one who did not recover fully had two additional recurrences of FP on the contralateral side without an associative etiologic finding those times. Acute otitis media was detected in 2/38 (5\%) patients, both receiving antibiotic treatment [20]. One of them recovered fully, the other one was left with mild synkineses and voluntary movement deficiency. One patient had an association with mycoplasma pneumonia as an etiologic factor [20] and was left with slight synkineses. One patient had congenital FP and 1 patient had neurofibromatosis type II [20] and recurring FP without total recovery. Etiology was unknown in 10/38 (26\%) of the cases [20] and 9/10 (90\%) recovered fully.

\section{Facial palsy recurrence}

At the time of the questionnaire and assessment visit, 2.3-4.6 years from the initial FP onset, 4 of the 38 (11\%) patients had had FP recurrence (Table 7). Two had experienced it on the same side of the face as the initial palsy, two on the contralateral side. The etiology for the recurrence was known for only one patient (neurofibromatosis). As mentioned previously, one patient had already had two recurrences (contralateral side to the initial palsy) without a known cause. In January 2020, patient charts for 43 of the initial 46 patients could be retrieved, 3 had moved out of the district. An additional 2 patients, who were among the 38 patients taking part in this follow-up study, had had a recurrence of FP after the follow-up questionnaire/visit. Thus, at the 10.3-12.6-year follow-up, at least 6/43 (14\%) of these children, teenagers, or now young adults had experienced an FP recurrence, only one with a known cause. The number could be even higher if someone had suffered recurrent FP without making contact with the local health-care system.

\section{Discussion}

\section{Applicability of the grading scales}

HB failed to be executable with half of the patients that had any sequelae findings as was FNGS in a quarter of the cases. We have previously shown in our own studies [13, 23, 24] and many colleagues in theirs $[14,15,25]$ that often the $\mathrm{HB}$ result is forced to be a compromise of voluntary muscle functions (forehead, eye, and mouth) since the recovery levels of different areas of the face can differ greatly. Additionally, resting symmetry and/or synkinesis findings that are in disagreement with the grade best representing the voluntary muscle function status must be ignored to be able to place the patient in only one HB grade. Thus, the interpretation of the scale is only known to the user. FNGS cannot be promoted either because of its inability to take certain resting symmetry findings into consideration since voluntary muscle function grade is linked to resting symmetry grade. From the three grading scales used, SB was the most applicable. Recent studies show SB gaining popularity especially when synkineses are assessed [14, 19].

Many of the studies on grading FP outcomes have used video recordings but investigators have also shown that grading face-to-face with the patient compared with grading from a video affects the results obtained especially concerning the grading of synkinesis [26]. There certainly is a definite need for an objective grading method for FP outcome.

\section{Facial palsy outcome}

Previous studies have suggested that younger children recover better from FP than older children do [5, 27-29]. In our face-to-face study, this was not true: the median age was much higher for the fully recovered children. Our nonfully recovered group was small (eight children) though, with each child's age having a significant effect, so the end result could be just a coincidence. However, it might not be, since studies contradicting the younger-the-better outcome also exist $[10,30]$.

We know from previous studies that assessments performed by the professionals differ from a patient's own assessments-both better and worse [31-33]. Sometimes the patients/caregivers have not noticed slight synkineses seen by the investigator. Also, it is easy to understand that the face can appear and function normally but still ache or feel stiff or weak, also addressing the fact that none of the grading scales used measures a patient's own sensations. The discrepancy between the questionnaire and face-to-face assessment of FP outcome was clearly shown in this study, which highlights the need to take this into consideration when making conclusions about FP outcome from different types of studies [11,28].

We question the previous assumptions that almost all children recover well from FP [4-11, 28] based on our current study and previous follow-up studies where the outcome has actually been assessed after at least 1 year from FP onset and face-to-face with the patient, not based on retrospective data from patient charts. Biebl et al. [34] recruited 56 (40\%) of 141 pediatric FP patients for a follow-up visit with a result of 44/56 (79\%) totally recovered to HB I grade. Nonetheless, they mention that slight 
weakness and facial asymmetry were noticeable in up to $50 \%$ of the patients. The patients had been assigned to HB grade I based on the voluntary muscle function recovery state and ignoring the sequelae findings, which disagreed. In their study, only $40 \%$ of the patients arrived for the follow-up visit. They ponder whether that was because the patients had recovered well or because they had remaining symptoms and did not want to be reminded of them. Similarly, in a study by Bagger-Sjöbäck et al. [33], of patients who were considered totally cured at 6 months, 3-5 years later $13 \%$ reported subjective symptoms and about half demonstrated signs of sequelae when assessed. In a previous study from our hospital, $69-77 \%$ of the pediatric FP patients recovered fully based on face-toface assessment (subjective symptoms were not asked for nor was a questionnaire used) [35].

Similarly, based on assessment, Skogman et al. [36] found $78 \%$ of the patients to be fully recovered, no questionnaire for subjective symptoms was used. In our present study, with meticulous reporting of also slight sequelae, $68 \%$ of the patients had recovered totally, but $35 \%$ of them reported subjective sequelae invisible to the assessor. Thus, there are now at least three separate studies on pediatric long-term FP outcome showing that $30-50 \%$ of patients whose voluntary muscle functions have recovered well experience at least subjective sequelae, and when meticulously assessing the FP outcome, they show mild to moderate sequelae also noticeable by the assessor. We can ask whether those findings are significant and the study by Biebl et al. [34] answers that they are-the social impact for the individual patient was high.

We conclude that in retrospective studies the full recovery and very good outcome results have often been joined, since they are from patient charts and not that specific. Results of 90-100\% recovery are predominant. Instead, when the long-term outcome is assessed faceto-face the full recovery result drops to $68-78 \%$ and even good recovery (very mild sequelae permitted) to $80-85 \%$, still leaving additional subjective sequelae unreported. These recovery rates resemble those of adults achieved by the same grading method as used in this study (SB) [22].

\section{Etiology and outcome}

When considering the outcome of FP based on etiology in this study, the patient numbers in each etiology category were too small to draw reliable conclusions. Previously it has been shown that the recovery of borreliosis FP patients does not differ from other etiologies [34-36] and that was the result also in this study.

\section{Facial palsy recurrence}

The very surprising result of our study was the recurrence rate: $14 \%$ in a 10 -year follow-up and $11 \%$ within less than 5 years. That is a lot compared with the $6-13 \%$ reported previously for the whole lifetime in adults $[28,29]$. It is hard to get a clear picture from the previous pediatric FP studies of how the information on recurrence rates has been gained, many of them not mentioning the follow-up time period. The following numbers could be found from the literature for the recurrence: 5.6\% [27], 6\% [37], 6.8\% [38], 6.2\% [8], 9\% [4]. Two studies from the same investigators have reported high recurrence numbers $(25 \%, 10 \%)$, but the numbers seem to reflect more the type of patients that have been referred to them [6, 39]. In our study, the 46 patients that took part in the initial prospective study [20] were consecutive pediatric FP patients from the whole district and the recurrence rate of their FP could be followed over 10 years. Considering this, our $14 \%$ recurrence rate was very high and surprising.

\section{Strengths and limitations}

The strength of this study was the consecutive nature of the patients from a previous pediatric facial palsy prospective study. We treated all pediatric facial palsy patients from the area in our tertiary referral center at the time of the study. Hence, the etiologies and facial palsy outcome should have reflected the objective reality.

The prospective study basis also brought limitations to the study. Facial palsy in children is far less frequent than in adults and our study patient number was low. The study was underpowered to find a statistically significant difference compared with studies reporting $90 \%$ or better recovery. For that, we would have needed at least 82 patients (calculations not shown). However, from a treating physician's perspective, our finding of a $70 \%$ recovery rate was quite different in comparison with the $90-100 \%$ reported in retrospective studies and, as such, we feel this has clinical significance.

\section{Conclusions}

Not all children recovered well from FP when meticulously assessed face-to-face. Patients also widely suffered from subjective sequelae affecting their quality of life. Even considering the whole lifetime, the observed palsy recurrence rate of $11 \%$ after 5 years and $14 \%$ after 10 years was surprisingly high, much higher than previously reported. SB was the most recommendable of the grading scales used. 
Funding Open access funding provided by University of Helsinki including Helsinki University Central Hospital. This work was supported by Helsinki University Hospital Research Funds. The funding source was not involved in the study design; in the collection, analysis, and interpretation of data; in the writing of the report; and in the decision to submit this manuscript for publication.

\section{Compliance with ethical standards}

Conflict of interest The authors declare that they have no conflict of interest.

Ethical approval The Ethics Committee of the Helsinki University Hospital approved the study and institutional research approval was granted. Prospective study part: all patients gave their written informed consent.

Open Access This article is licensed under a Creative Commons Attribution 4.0 International License, which permits use, sharing, adaptation, distribution and reproduction in any medium or format, as long as you give appropriate credit to the original author(s) and the source, provide a link to the Creative Commons licence, and indicate if changes were made. The images or other third party material in this article are included in the article's Creative Commons licence, unless indicated otherwise in a credit line to the material. If material is not included in the article's Creative Commons licence and your intended use is not permitted by statutory regulation or exceeds the permitted use, you will need to obtain permission directly from the copyright holder. To view a copy of this licence, visit http://creativecommons.org/licenses/by/4.0/.

\section{References}

1. Fu L, Bundy C, Sadiq SA (2011) Psychological distress in people with disfigurement from facial palsy. Eye 25(10):1322-1326

2. Beurskens CHG, Oosterhof J, der Sanden N-V, Maria WG (2010) Frequency and location of synkineses in patients with peripheral facial nerve paresis. Otol Neurotol 31(4):671-675

3. Bylund N, Jensson D, Enghag S et al (2017) Synkinesis in Bell's palsy in a randomised controlled trial. Clin Otolaryngol 42(3):673-680

4. Karalok ZS, Taskin BD, Ozturk Z, Gurkas E, Koc TB, Guven A (2018) Childhood peripheral facial palsy. Childs Nerv Syst 34(5):911-917

5. Unuvar E, Oguz F, Sidal M, Kilic A (1999) Corticosteroid treatment of childhood Bell's palsy. Pediatr Neurol 21(5):814-816

6. Chen W, Wong V (2005) Prognosis of Bell's palsy in childrenanalysis of 29 cases. Brain Dev 27(7):504-508

7. Jenke AC, Stoek L, Zilbauer M, Wirth S, Borusiak P (2011) Facial palsy: etiology, outcome and management in children. Eur J Paediatr Neurol 15(3):209-213

8. Yilmaz U, Cubukcu D, Yilmaz TS, Akinci G, Ozcan M, Guzel O (2014) Peripheral facial palsy in children. J Child Neurol 29(11):1473-1478

9. Wang C, Chang Y, Shih H, Chen C, Chen J (2010) Facial palsy in children: emergency department management and outcome. Pediatr Emerg Care 26(2):121-125

10. Karatoprak E, Yilmaz S (2019) Prognostic factors associated with recovery in children with Bell's palsy. J Child Neurol 34(14):891-896
11. Drack FD, Weissert M (2013) Outcome of peripheral facial palsy in children-a catamnestic study. Eur J Paediatr Neurol 17(2):185-191

12. House JW, Brackmann DE (1985) Facial nerve grading system. Otolaryngol Head Neck Surg 93(2):146-147

13. Kanerva M, Poussa T, Pitkäranta A (2006) Sunnybrook and House-Brackmann facial grading systems: intrarater repeatability and interrater agreement. Otolaryngol Head Neck Surg 135(6):865-871

14. Fattah AY, Gurusinghe ADR, Gavilan J et al (2015) Facial nerve grading instruments: systematic review of the literature and suggestion for uniformity. Plast Reconstr Surg 135(2):569-579

15. Scheller $C$, Wienke A, Tatagiba $M$ et al (2017) Interobserver variability of the House-Brackmann facial nerve grading system for the analysis of a randomized multi-center phase III trial. Acta Neurochir (Wien) 159(4):733-738

16. Vrabec JT, Backous DD, Djalilian HR et al (2009) Facial nerve grading system 2.0. Otolaryngol Head Neck Surg 140(4):445-450

17. Neely JG, Cherian NG, Dickerson CB, Nedzelski JM (2010) Sunnybrook facial grading system: reliability and criteria for grading. Laryngoscope 120(5):1038-1045

18. Ross BG, Fradet G, Nedzelski JM (1996) Development of a sensitive clinical facial grading system. Otolaryngol Head Neck Surg 114(3):380-386

19. Berner JE, Kamalathevan P, Kyriazidis I, Nduka C (2019) Facial synkinesis outcome measures: a systematic review of the available grading systems and a Delphi study to identify the steps towards a consensus. J Plast Reconstr Aesthet Surg 72(6):946-963

20. Kanerva M, Nissinen J, Moilanen K, Maki M, Lahdenne P, Pitkäranta A (2013) Microbiologic findings in acute facial palsy in children. Otol Neurotol 34(7):82

21. Mehta RP, WernickRobinson M, Hadlock TA (2007) Validation of the synkinesis assessment questionnaire. Laryngoscope 117(5):923-926

22. Engström M, Berg T, Stjernquist-Desatnik A et al (2008) Prednisolone and valaciclovir in Bell's palsy: a randomised, double-blind, placebo-controlled, multicentre trial. Lancet neurol 7(11):993-1000

23. Kanerva M, Jonsson L, Berg T et al (2011) Sunnybrook and House-Brackmann systems in 5397 facial gradings. Otolaryngol Head Neck Surg 144(4):570-574

24. Kanerva M, Jones S, Pitkäranta A (2020) Ramsay Hunt Syndrome: long-term facial palsy outcome assessed face-to-face by three different grading scales and compared to patient self-assessment. Eur Arch Otorhinolaryngol. https://doi.org/10.1007/s0040 5-020-06251-w

25. Coulson SE, Croxson GR, Adams RD, O'Dwyer NJ (2005) Reliability of the "Sydney," "Sunnybrook," and "House Brackmann" facial grading systems to assess voluntary movement and synkinesis after facial nerve paralysis. Otolaryngol Head Neck Surg 132(4):543-549

26. Tan JR, Coulson S, Keep M (2019) Face-to-face versus video assessment of facial paralysis: implications for telemedicine. $\mathrm{J}$ Med Internet Res 21(4):e11109

27. Lee Y, SooYoon H, Yeo SG, Lee EH (2020) Factors associated with fast recovery of Bell palsy in children. J Child Neurol 35(1):71-76

28. Peitersen E (2002) Bell's palsy: The spontaneous course of 2,500 peripheral facial nerve palsies of different etiologies. Acta Otolaryngol Suppl 549:4-30

29. Devriese PP, Moesker WH (1988) The natural history of facial paralysis in herpes zoster. Clin Otolaryngol Allied Sci 13(4):289-298

30. Ozkale Y, Erol I, Saygi S, Yilmaz I (2015) Overview of pediatric peripheral facial nerve paralysis: analysis of 40 patients. J Child Neurol 30(2):193-199 
31. Gyori E, Przestrzelski C, Pona I et al (2018) Quality of life and functional assessment of facial palsy patients: a questionnaire study. Int J Surg 55:92-97

32. Ikeda M, Nakazato H, Hiroshige K, Abiko Y, Sugiura M (2003) To what extent do evaluations of facial paralysis by physicians coincide with self-evaluations by patients: Comparison of the Yanagihara method, the House-Brackmann method, and self-evaluation by patients. Otol Neurotol 24(2):334-338

33. Bagger-Sjöbäck D, Remahl S, Ericsson M (2005) Long-term outcome of facial palsy in neuroborreliosis. Otol Neurotol 26(4):790-795

34. Biebl A, Lechner E, Hroncek K et al (2013) Facial nerve paralysis in children: Is it as benign as supposed? Pediatr Neurol 49(3):178-181

35. Peltomaa M, Saxen H, Seppälä I, Viljanen M, Pyykkö I (1998) Paediatric facial paralysis caused by Lyme borreliosis: a prospective and retrospective analysis. Scand J Infect Dis 30(3):269-275
36. Skogman BH, Croner S, Odkvist L (2003) Acute facial palsy in children-a 2-year follow-up study with focus on Lyme neuroborreliosis. Int J Pediatr Otorhinolaryngol 67(6):597-602

37. Eidlitz-Markus T, Gilai A, Mimouni M, Shuper A (2001) Recurrent facial nerve palsy in paediatric patients. Eur J Pediatr 160(11):659-663

38. Shih W, Tseng F, Yeh T, Hsu C, Chen Y (2009) Outcomes of facial palsy in children. Acta Otolaryngol (Stockh) 129(8):915-920

39. Wong V (1995) Outcome of facial nerve palsy in 24 children. Brain Dev 17(4):294-302

Publisher's Note Springer Nature remains neutral with regard to jurisdictional claims in published maps and institutional affiliations. 